A - Research concept and design

B - Collection and/or assembly of data

$\mathrm{C}$ - Data analysis and interpretation

D - Writing the article

E - Critical revision of the article

F - Final approval of article

\section{Lumbopelvic pain problem in pregnant women}

\author{
Michalina Walczak*A-F (D), Aneta Dąbek ${ }^{A, E, F}$ (iD \\ Józef Piłsudski University of Physical Education, Warsaw, Poland
}

*Correspondence: Michalina Urszula Walczak; Józef Piłsudski University of Physical Education in Warsaw, Poland; email: walczakmichalina95@gmail.com

\begin{abstract}
Introduction: Lumbopelvic pain (LPP) is clinically diverse and difficult to treat medical problem. Changes during pregnancy and confinement conduce the appearance of pain complaints. LPP proper differential diagnosis and education constitute the basis of properly selected treatment. The aim of the study was to establish the LPP frequency in pregnant women. Additionally, the daily living activities limitations level was defined.

Materials and methods : 211 pregnant women took part in the study. The study was performed with the use of advanced online questionnaire. The research tool consisted of: original questionnaire, International Physical Activity Questionnaire - IPAQ (shortened Polish version) and Oswestry Disability Index (ODI).

Results: On the basis of conducted studies, the LPP was diagnosed in majority $(80.1 \%)$ of tested women. There were statistically significant correlations between the pain intensity and age $(p=0.023, r=-0.16)$ and education $(p=0.013$, $r=-0.17)$. It has been proven that there is a statistically significant correlation between the pain intensity, BMI ( $p=0.002$, $\mathrm{r}=0.22)$ and physical activity level $(\mathrm{p}=0.048, \mathrm{r}=0.14)$. It has been stated that $65.4 \%$ research subjects had no significant limitations in performing daily living activities.

Conclusions: The lumbopelvic pain applies to majority of pregnant women in the study. The risk of LPP increases with BMI growth. LPP occurs less frequently in women with higher education and in older ones. In majority of cases LPP does not cause limitations in daily living activities.
\end{abstract}

Keywords: lumbopelvic pain, physical activity, pregnancy

\section{Introduction}

The lumbopelvic pain (LPP) divides into lumbar pain (LP), pelvic girdle pain (PGP) and mixed pain [1]. Each kind of the pain has got various and usually complex clinical picture. Lumbar pain is similar to the pain that is experienced by women who are not pregnant. It is usually located in the lumbar spine area, just above the sacrum. Prevertebral muscles tenderness is often associated with LP. Pelvic girdle pain, on the other hand, is described as deep, stabbing, one or both-sided, recurring or constant pain. It is usually located between posterior ridge of the iliac crest and gluteal sulcus. It may radiate towards femur, knee or crus [2]. Although differential diagnosis may cause a lot of problems, it is worth taking the challenge due to therapeutic benefits. 
Each kind of pain has got different cause and it requires different therapeutic practice [2-4]. Pregnancy is a huge challenge for woman's organism. Posture change, significant weight gain and changes in hormone balance occur at that time and they cause lumbopelvic pain. Center of gravity shifts few centimeters to the front and in order to balance it, the lumbar lordosis increases. Posture changes cause imbalance between pelvis and lumbar spine. Typical muscular disorders such as contracture of hip flexor and erector spinae with simultaneous weakness of abdominal muscles and hip extensors appear [5]. Pregnant women with gluteus medius weakness experience lumbopelvic pain six to eight times more often than in cases when gluteus medius is wrong enough [6]. On the other hand, overstretched piriformis muscle is usually responsible for piriformis syndrome that causes pain mainly in gluteal region [7]. Transversus abdominis muscle, which stretches and weakens during pregnancy, has got the highest influence on the stabilization of the lumbo-pelvic complex. Transversus abdominis muscle is responsible for intra-abdominal pressure elevation, fascia tension, sacroiliac joint and pubic symphysis compression [8].

Between 20th and 26th week of pregnancy, due to hormonal activity (relaxin and estrogens), relaxation of ligaments stabilizing sacroiliac joints and pubic symphysis appears. It causes much greater pelvic mobility. Pelvis positions itself in excessive anteversion. Additionally, weight gain and abdominal muscles stretching impair core stability and finally cause lumbopelvic pain $[9,10]$. Contrary to popular belief, herniated nucleus pulpous with associated disc-radicular syndrome is rare during pregnancy (1 in 10000 cases)[5].

Most pregnant women believe that lumbopelvic pain is inevitable. Only $50 \%$ of women with LPP seek medical attention [11]. Education that includes information about risk factors, work ergonomics, relaxation techniques and pain relieving techniques, is an important factor in the therapy of people with LPP $[12,13]$.

Physical activity is significant factor that alleviates the LPP and influences the course of pregnancy. Regular mild physical activity counteracts excessive weight gain, helps maintaining proper muscle tone and joint range of motion and it positively affects posture that changes during pregnancy. Other benefits of physical activity include lower risk of swelling, varicose veins and it improves intestinal peristalsis. What is more, physically active women more often delivers by forces of nature and delivery duration is averagely shorter by 2-3 hours. Moreover, active pregnant women rarely experience premature birth, prolonged pregnancy or Caesarean section. All above benefits cause faster postpartum regeneration and relieve pain in lumbar spine area and pelvis $[14,15]$.

The main aim of this study was to evaluate the frequency of lumbopelvic pain in pregnant women and to identify LPP risk factors. Additional aim was to evaluate the level of functional activity impairment caused by lumbopelvic pain.

\section{Materials and methods}

The study was performed in May and June 2020 . 211 women were enrolled in the study. Inclusion criteria included proper course of pregnancy and age between 18 and 45 years. Exclusion criteria included: scoliosis and Scheuermann's disease. For majority of women it was their first pregnancy (56.3\%). The following table presents biometric data (table 1).

Due to epidemic situation the study was performed with the use of advanced online questionnaire. It was published on Internet groups for pregnant women and antenatal classes webpages. The questionnaire was

Tab. 1. Participants characteristics

\begin{tabular}{lccc}
\hline \multirow{2}{*}{ Body composition } & \multicolumn{3}{c}{ Descriptive statistics } \\
\cline { 2 - 4 } & $\mathrm{N}$ & Min & Max \\
\hline Age [years] & 211 & 17.00 & 40.00 \\
Height $[\mathrm{cm}]$ & 211 & 147.00 & 180.00 \\
Body weight during pregnancy $[\mathrm{kg}]$ & 211 & 44.00 & 134.00 \\
Body weight before pregnancy $[\mathrm{kg}]$ & 211 & 43.00 & 127.00 \\
BMI during pregnancy $\left[\mathrm{kg} / \mathrm{m}^{2}\right]$ & 211 & 14.37 & 47.48 \\
BMI before pregnancy $\left[\mathrm{kg} / \mathrm{m}^{2}\right]$ & 211 & 15.42 & 43.94 \\
Week of pregnancy & 211 & 4 & 40 \\
\hline
\end{tabular}

$\mathrm{N}$ - number of observations; Min - minimum; Max - maximum. 
anonymous and voluntary. The questions concerned age, education, character of work, course of pregnancy, pain. Additionally, women filled International Physical Activity Questionnaire - IPAQ (shortened Polish version) and Oswestry Disability Index (ODI).

\section{Statistical analysis}

The variables were analyzed with the use of Statistica 13.1 program produced by StatSoft company. ShapiroWalk test verified concordance of distribution with normal distribution. Two-tailed test was used in the study. Variance homogeneity was evaluated with Levene'a test. Spearman's rank correlation coefficient was used to measure the relations between the variables. $\mathrm{P}<0.05$ was established as the level of statistical significance.

\section{Results}

The analysis of lumbopelvic pain incidence among pregnant women showed that pain was experienced by 169 participants $(80.1 \%)$ (Fig. 1$)$.
Regarding the type of pain, majority of women (141 participants $-67.8 \%$ ) experienced pain in the lumbar spine area (Tab. 2).

Analysis of data acquired with the use of VAS showed that moderate pain intensity was $4.11 \pm 2.71$ points (Tab. 3).

Statistically significant negative correlations were demonstrated between pain intensity and participants' age $(\mathrm{p}=0.023, \mathrm{r}=-0.16)$ and education $(\mathrm{p}=0.013, \mathrm{r}=-0.17)$. It means that older women with better education experienced less pain. On the other hand, correlations between pain intensity and BMI $(\mathrm{p}=0.002, \mathrm{r}=0.22)$ and physical activity level $(p=0.048, r=0.14)$ were positive. It means that participants with higher BMI and who used higher energy expenditure on physical activity, experienced more pain (Tab. 4).

Regarding data acquired from the Oswestry questionnaire, $65.4 \%$ of pregnant women had no significant limitations in daily living activities. Fig. 2 contains specific data concerning limitations in daily living activities.

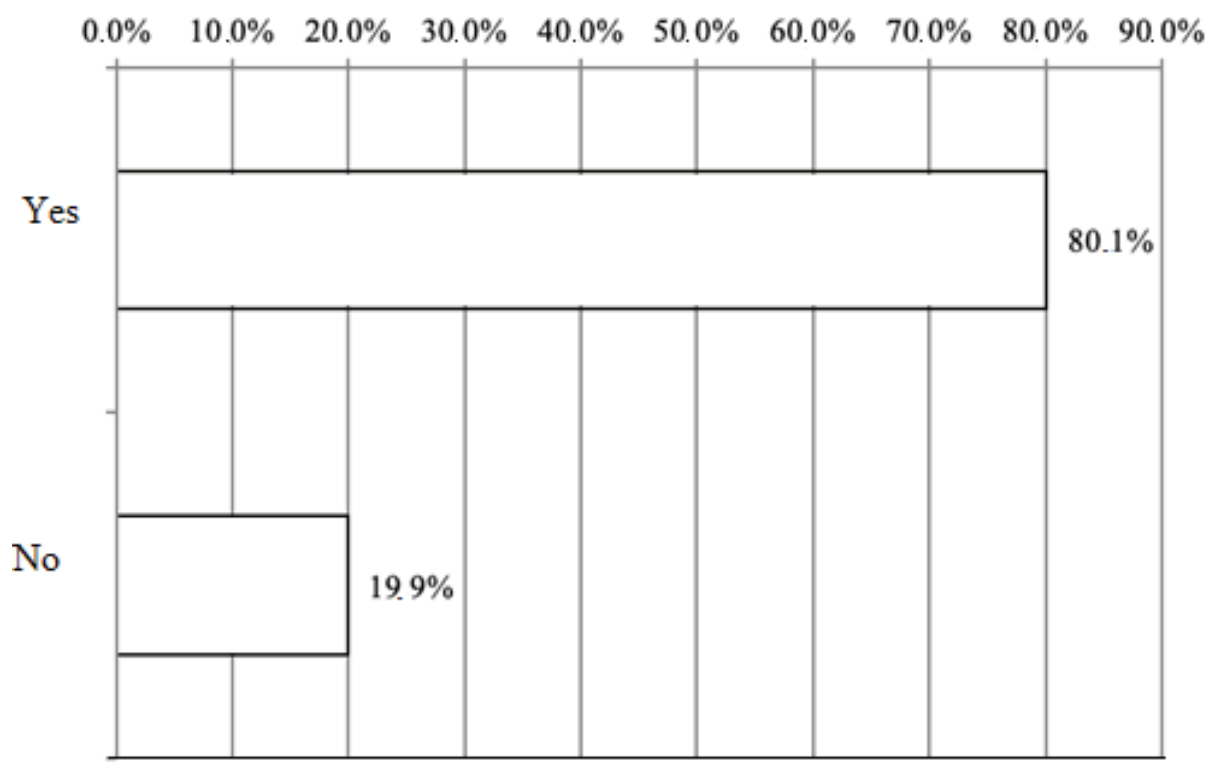

Fig. 1. Pain incidence among pregnant women

Tab. 2. Type of pain

\begin{tabular}{lcc}
\hline Type of pain experienced during pregnancy & $\mathrm{N}$ & $\%$ \\
\hline Pain in the lumbar spine area & 143 & $67.8 \%$ \\
Pain in the pelvic girdle area & 117 & $55.5 \%$ \\
Lumbopelvic pain (mixed pain) & 103 & $48.8 \%$ \\
\hline
\end{tabular}

$\mathrm{N}$ - number of observations. 
Tab. 3. Pain intensity during pregnancy

\begin{tabular}{lcccc}
\hline \multirow{2}{*}{ VAS pain scale } & \multicolumn{4}{c}{ Descriptive statistics } \\
\cline { 2 - 5 } & $\mathrm{N}$ & $\bar{x}$ & Min. & Max. \\
\hline$[0-10$ pt. $]$ & 211 & 4.11 & 0.00 & 10.00 \\
\hline
\end{tabular}

$\mathrm{N}$ - number of observations; Min - minimum; Max - maximum.

Tab. 4. Correlations between pain intensity and selected factors

\begin{tabular}{lcc}
\hline Variables & $\mathrm{r}$ & $\mathrm{p}$ \\
\hline Pain intensity versus pain & -0.16 & 0.023 \\
$\begin{array}{l}\text { Pain intensity versus age } \\
\begin{array}{l}\text { Pain intensity versus pregnancy } \\
\text { duration }\end{array}\end{array}$ & -0.17 & 0.013 \\
$\begin{array}{l}\text { Pain intensity versus BMI } \\
\text { during pregnancy }\end{array}$ & 0.0721 \\
$\begin{array}{l}\text { Pain intensity versus BMI before } \\
\text { pregnancy }\end{array}$ & 0.21 & 0.002 \\
$\begin{array}{l}\text { Pain intensity versus total IPAQ } \\
\text { activity }\end{array}$ & 0.14 & 0.048 \\
\hline
\end{tabular}

$\mathrm{r}$ - Spearman's rank correlation coefficient.

The greatest difficulties connected with spine and/or pelvic pain were experienced while standing (1.58 pt), sitting (1.53 pt) and lifting (1.07 pt) and travelling (1.03 pt). Specific data is presented in table 5 .
Tab. 5. Pain experience in various activities

\begin{tabular}{lccc}
\hline & $\mathrm{N}$ & Min. & Max. \\
\hline Pain intensity & 211 & 0.00 & 3.00 \\
Everyday activities & 211 & 0.00 & 3.00 \\
Walking & 211 & 0.00 & 2.00 \\
Lifting & 211 & 0.00 & 5.00 \\
Sitting & 211 & 0.00 & 4.00 \\
Standing & 211 & 0.00 & 4.00 \\
Sleeping & 211 & 0.00 & 5.00 \\
Sex life & 211 & 0.00 & 5.00 \\
Social life & 211 & 0.00 & 5.00 \\
Travelling & 211 & 0.00 & 6.00 \\
Total [\%] & 211 & 0.00 & 70.00 \\
\hline
\end{tabular}

$\mathrm{N}$ - number of observations; Min - minimum; Max - maximum.

General level of physical activity among the majority of participants $(69.7 \%)$ was assessed as moderate. Tab. 6 contains more information concerning general physical activity.

Tab. 6. General level of physical activity

\begin{tabular}{lcc}
\hline General physical activity & $\mathrm{N}$ & $\%$ \\
\hline Low & 27 & $12.8 \%$ \\
Moderate & 147 & $69.7 \%$ \\
High & 37 & $17.5 \%$ \\
Total & 211 & $100.0 \%$ \\
\hline
\end{tabular}

$\mathrm{N}$-number of observations

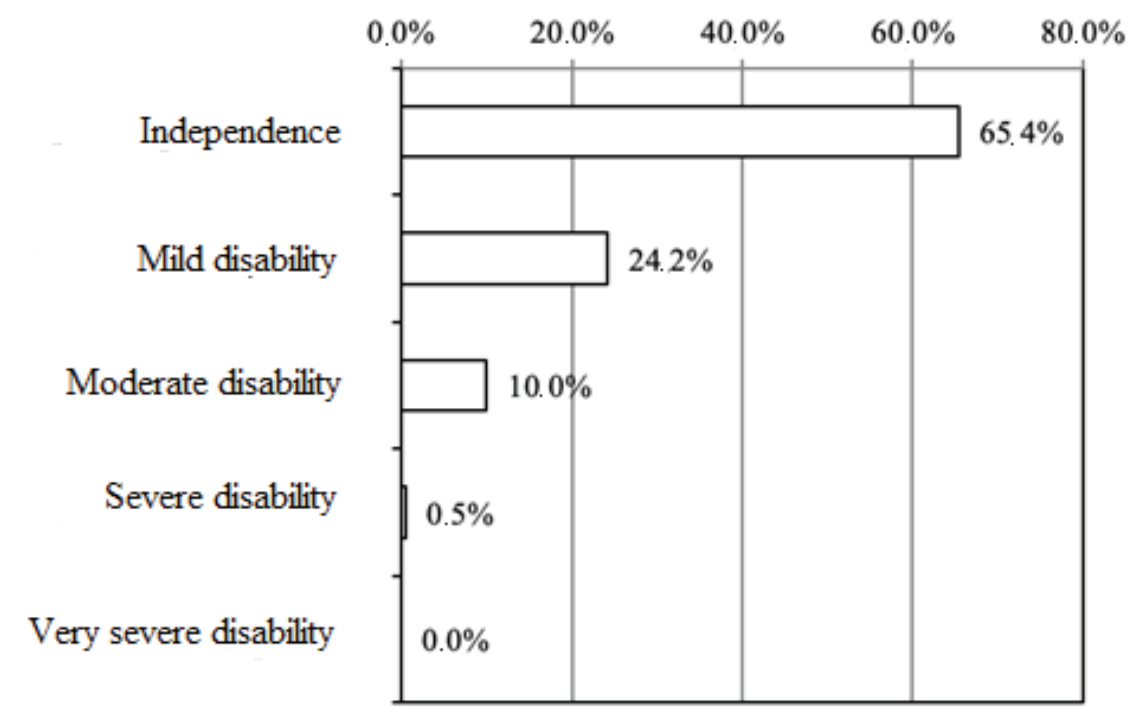

Fig. 2. Disability level of the participants 


\section{Discussion}

Author's own research confirmed high frequency of lumbopelvic pain occurrence in pregnant women. $80.1 \%$ participants reported moderate intensity pain, VAS $=4.11$. Similar results were obtained by Östgaard and Andersson who claimed that pregnant women experienced pain of 4.4 out of 10 [16]. Research performed by Pierre et al., showed that $71 \%$ of pregnant women experienced lumbopelvic pain intensity of VAS $=6.5$. The authors observed PGP in 22\%, LP in $11 \%$ and LPP in 33\% of participants [13]. Starzec et al. compared 189 pregnant women with 36 women in controlled group. It was proven that LPP is significantly more frequent in pregnant women. Authors suggest that it is due to reducing daily living activities during pregnancy. Lumbopelvic pain was present in $65 \%$ of pregnant women. VAS pain intensity amounted to an average of 4.84 in case of LP and 4.87 in PGP [17].

According to many authors, high BMI is a predisposing factor for lumbopelvic pain occurrence [18-20]. This aspect was proven in the above study. Moreover, Morgen proved that higher BMI is a significant factor for lumbopelvic pain occurrence even after delivery [17]. According to European guidelines, physical exercises and relaxation show great importance in spine pain treatment $[4,19]$. The above guidelines have not been proven in this study. Women who used higher energy expenditure on physical activity, experienced more pain. It can be explained by the fact that majority of active women had high BMI.

On the basis of performed test I deduce that more educated women experienced lumbopelvic pain less often. Similar findings were presented by Chang et al., who claimed that women with secondary or primary education reported higher pain intensity that women with higher education [20]. The results may have few possible explanations. Firstly, women with lower education level could have less knowledge about LPP prevention and treatment than women with higher education. Secondly, education level is bound to general socio-economic status, so women with lower level of education could have limited economic resources [22]. Thirdly, women with lower level of education had less support from third parties [23].

Negative correlation between lumbopelvic pain intensity and participants' age is an interesting problem that requires further research. It is difficult to logically explain this issue. It seems that similarly to the case of education level, younger people may have less knowledge about LPP prevention and treatment and it translates to higher pain intensity.

During the research, the participants reported problem with defining the pain. Although the questionnaire was accompanied with illustrations and descriptions, a lot of women had difficulties in qualifying their pain into one of the three groups: LP, PGP or LPP. The possible cause of these problems might have been low knowledge level of anatomy, palpation or pathomechanics. Simons claims that muscle dysfunctions are the most frequent cause of pain in lumbar spine and pelvis among pregnant women [5,7]. During pregnancy, some muscles decrease and other increase in tone. Increased muscle tone leads to the development of oversensitive and palpable nodules, so called trigger points. They are painful under pressure and cause pain radiating to various directions. According Simons, lumbar pain develops due to trigger points activation in the following muscles: gluteus minimus, multifidus, iliopsoas, musculus longissimus or rectus abdominis [7]. Due to the fact that the points are easy to palpate, they make proper diagnosis easier for the physiotherapist. People with no medical education may have difficulties in finding the trigger points and in diagnosis itself.

The number of clinicians who consider lumbopelvic pain as physiological and requiring no treatment is worrying $[11,24,25]$. Although, abdominal muscles and pelvic floor stretching during pregnancy and confinement is to some extent physiological, it always requires physiotherapist consultation. Neglecting the above changes impairs the stabilization of the spine and causes pain intensification. Oswerty Disability Index, which allows to measure the way spinal pain influences everyday life, showed that $24.2 \%$ participants got mild disability and $10 \%$ got moderate disability. Biernat et al. claim that filling the questionnaire individually may lead to overestimation. Moreover, the authors believe that a person conducting a survey with the use of ODI and IPAQ should be qualified in the field [23].

Conducted study has practical value. Obtained data show the scale of the problem connected with lumbopelvic pain among pregnant women. It is of great importance that LPP specialists focus on risk factors. The research is also a motivation for preventive actions. It is worth continuing the studies under physiotherapist supervision. Although the questionnaire had precise instructions, it was difficult for the participants to diversify the kinds of pain. Due to epidemic situation, it was impossible to conduct the study in direct contact conditions.

\section{Conclusions}

1. The lumbopelvic pain applies to majority of pregnant women in the study.

2. The risk of LPP increases with BMI growth.

3. LPP occurs less frequently in women with higher education and in older ones. 
4. In majority of cases LPP does not cause limitations in daily living activities.

\section{References}

1. Starzec M, Truszczyńska A. Pregnancy-.related lumbopelvic pain-treatment modalities. Adv Rehab. 2017; 31(2); 69-78.

2. Wu WH, Meijer OG, Uegaki K et al. Pregnancy-related pelvic girdle pain (PPP), I: terminology, clinical presentation, and prevalence. Eur Spine J. 2004; 575-89.

3. Vianin M. Psychometric properties and clinical usefulness of the Oswestry Disability Index. J Chiropr Med. 2008; 7: 161-3.

4. Vleeming A, Albert HB, Östgaard HC, Sturesson B, Stuge B. European guidelines for the diagnosis and treatment of pelvic girdle pain. Eur Spine J. 2008; 17: 794-819.

5. Majchrzycki M, Mrozikiewicz PM, Kocur P, et al. Low back pain in pregnant women. Ginekol Pol. 2010; 81: 851-5.

6. Jasiński R, Skrzyniarz M, Zasławski R. Back pain in pregnant women. Ginekol Pol. 2000; 71: 231-6.

7. Simons D. New views of myofascial trigger points: etiology and diagnosis. Arch Phys Med Rehabil. 2008; 89: $157-9$.

8. Hodges P. Is there a role for transversus abdominis in lumbo-pelvic stability? Man Ther. 1999; 4: 74-86.

9. Urtnowska K, Bułatowicz I, Radzimińska A, Woźniak M, Wiśniewski J, Żukow W. Physiological changes in the locomotor system of a pregnant and related lumbar-sacral pain-examination of the degree of feeling back pain during properly running pregnancy. J Educ Health Sport. 2015; 5(7): 105-16.

10. Dumas GA, Reid JG, Griffin MP, McGrath MJ. Exercise, posture, and back pain during pregnancy. Part 1. Exercise and posture. Clin Biomech. 1995; 98-103.

11. Katonis P, Kampouroglou A, Aggelopoulos A, et al. Pregnancy related low back pain. Hippokratia. 2011; 15: 205-10.

12. Pelvic, Obstetric and Gynaecological Physiotherapy (POGP) Pregnancy-related pelvic girdle pain: guidance for health professionals. 2015, [cited 2016 Jan 10]. Available from: https://pogp.csp.org.uk/system/ files/pogp-pgppros_1.

13. Pierce H, Homer CS, Dahlen HG, King J. Pregnancy-related lumbopelvic pain: listening to Australian women. Nurs Res Pract [Internet] 2012 [cited 2015 Dec 13]. Available from: http://www.hindawi.com/ journals/nrp/2012/387428/

14. Torbè D, Torbè A, Ćwiek D. Aktywność fizyczna kobiet w ciąży o fizjologicznym przebiegu. Nowa Med. 2013; 174-9.

15. Parkitna O, Witkoś J, Onik G, Budziosz J, Sieroń K. Aktywność fizyczna w ciąży i jej wpływ na przebieg ciąży i porodu. Ostry dyżur: 2017; 10(1): 16-22.

16. Ostgaard HC, Andersson GB, Schultz AB, Miller JA. Influence of some biomechanical factors on low-back pain in pregnancy. Spine. 1993; 18: 61-5.

17. Starzec M, Truszczyńska-Baszak A, Tarnowski A. Pregnancy-related lumbar and Pelvic girdle pain in Polish women. Clin Exp Obstet Gynecol. 2018; 2: 194-7.

18. Gutke A, Betten C, Degerskar K, Pousette S, Fagevik Olsen M. Treatments for pregnancy-related lumbopelvic pain: a systematic review of physiotherapy modalities. Acta Obstet Gynecol Scand. 2015; 94: 1156-7.

19. Mogren IM. BMI, pain and hyper-mobility are determinants of long-term outcome for women with low back pain and pelvic pain during pregnancy. Eur Spine J. 2006; 15: 1093-102.

20. Chang HY, Jensen MP, Yang YL, et al. Risk factors of pregnancy-related lumbopelvic pain: a biopsychosocial approach. J Clin Nurs. 2012; 21: 1274-83.

21. Pennick VE, Young G. Interventions for preventing and treating pelvic and back pain in pregnancy. Cochrane Database Syst Rev. 2007; 2: 1-25.

22. Latza U, Kohlmann T, Deck R, Raspe H. Influence of occupational factors on the relation between socioeconomic status and self-reported back pain in a population-based sample of German adults with back pain. Spine. 2000; 25: 1390-7.

23. Biernat E, Piątkowska M, Gajewski AK. Participation in sport, motor leisure activities and physical activity of teachers from two different universities. In: Czyż E, Viviani F (ed.). New Horizons Wrocław: Elsevier Urban \& Partner. 2006, p. 25-33.

24. Jachacz-Łopata M, Milka D. Rozejście mięśnia prostego brzucha. Terapia kompleksowa. MedPharm. 2019; $1-51$.

25. Lardon E, St-Laurent A, Babineau V, Descarreaux M, Ruchat SM. Lumbopelvic pain, anxiety, physical activity and mode of conception: a prospective cohort study of pregnant women. BMJ Open. 2018; 8(11): e022508. 